\title{
Effects of resident species on recruitment into a community: larval settlement versus post-settlement mortality in the oyster Crassostrea virginica
}

\author{
Richard W. Osman ${ }^{1}$, Robert B. Whitlatch ${ }^{2}$, Roman N. Zajac ${ }^{3, *}$ \\ ${ }^{1}$ Academy of Natural Sciences, Benedict Estuarine Research Laboratory, Benedict, Maryland 20612, USA \\ ${ }^{2}$ Department of Marine Sciences, The University of Connecticut, Groton, Connecticut 06340, USA \\ ${ }^{3}$ Department of Biology and Environmental Sciences, The University of New Haven, West Haven, Connecticut 06515, USA
}

\begin{abstract}
Laboratory and field experiments revealed that a variety of species of common, sessile invertebrates, including barnacles, ascidians, and bryozoans, affected the settlement and post-settlement abundance of the oyster Crassostrea virginica (Gmelin). While the nature of the effects varied, most species both reduced oyster settlement by covering and removing substrate available for attachment, and increased settlement on adjacent surfaces. The solitary ascidians Ciona intestinalis (L.) and Styela clava (Herdman), were found to be predators of oyster larvae. Post-settlement survivorship and growth were also strongly affected by the presence of sessile species. In most cases the effects were negative and correlated with the abundances of the species. Data suggest that competition for planktonic food was the mostly likely cause of reduced growth and survivorship. For many resident species, the combination of reduced oyster settlement on their own exposed surfaces, increased settlement on substrate adjacent to them, and decreased post-settlement survivorship in their presence resulted in these species having little effect on net recruitment. These results demonstrate the need for distinguishing interactions among benthic invertebrate populations during the period from settlement to recruitment.
\end{abstract}

\section{INTRODUCTION}

Fluctuations in the recruitment of individuals from a largely unknown larval pool have long been viewed as contributing to the spatial and temporal variability within marine benthic communities (e.g. Baggerman 1953, Pratt 1953, Thorson 1966, Mileikovsky 1969). More recently, the relationships between recruitment variation and later interactions among established adults have been a focus (e.g. Sale 1977, 1978, 1979, 1982. Grosberg 1982, Eckman 1983, Hannan 1984, Underwood \& Denley 1984, Wethey 1984, 1985, Young \& Chia 1984, Caffey 1985, Roughgarden et al. 1985, Gotelli 1987). However, because recruitment combines both larval settlement and post-settlement mortality, the importance of each to species distributions is often unclear (Underwood \& Denley 1984). This is particu-

- Order of authorship alphabetical larly true for community-level investigations which examine the net effects of recruitment. To be observed at all, a recruit has attained a minimum size and has been resident in the benthic population for some time.

Studies of larval settlement have generally concentrated on the ability of the larva to select a habitat, with an emphasis on the physical and chemical cues that induce larval metamorphosis and settlement (e.g. Meadows \& Champbell 1972, Crisp 1974, Gray 1974, Scheltema 1974, Chia \& Rice 1978, Day \& McEdward 1984). Settlement is thus viewed as an active larval process. In this context, resident adults have been found to (1) reduce the rate of settlement, by either preying on the larvae or usurping the available space (e.g. Woodin 1976, 1978, 1983, Todd \& Doyle 1981, Whitlatch \& Zajac 1985; but see Gallagher et al. 1983), (2) increase settlement through gregarious responses (e.g. Crisp \& Knight-Jones 1953, Barnett \& Crisp 1979, Dixon 1981, Scheltema et al. 1981, Schmidt 1982, Jen- 
sen \& Morse 1984), or (3) alter settlement by influencing current flow or bottom boundary layers (Butman 1987).

In contrast to larval settlement, little is known about how resident species affect the post-settlement mortality and growth of potential recruits. The goal of this research was to isolate the effects of resident species on both settlement and post-settlement processes and determine their relationship to recruitment. The recruiting species was the oyster Crassostrea virginica (Gmelin), and we examined its relationship to common sessile species with which it co-occurs.

\section{GENERAL METHODS}

Three series of experiments were conducted ${ }_{i}$ two in 1986 and one between May and July 1987 (Table 1). The Series 1 experiments formed the core of the study and were designed to delineate the effects of a wide array of epifaunal species on the larval settlement, post-settlement juvenile mortality and growth, and the resultant recruitment of oysters. Series 2 experiments were conducted to test specific hypotheses regarding observations made during the Series 1 experiments. Finally, in Series 3 earlier experiments were modified and repeated to examine variation between years and to correct a problem in the design of 2 Series 1 experiments. Because the rationale for each series of experiments resulted from the analyses of the experiments in earlier series, we will present the methods and results for this study by series.
In most experiments, treatments consisted of substrates of identical size which contained different densities of a single taxon of sessile invertebrates. Taxa used were those with which oysters were likely to interact. Interactions of oysters with each taxon were followed through 2 arbitrary oyster life-stages: a larval settlement and attachment stage of less than $1 \mathrm{~d}$ and a juvenile or post-settlement period of 1 to $2 \mathrm{mo}$.

Experimental surfaces were square panels $100 \mathrm{~cm}^{2}$ in size and constructed from grey plastic (PVC). Panels were abraded to produce a rough surface texture, attached horizontally to field racks, and their undersides were used. Each rack held 16 panels, and ca 100 panels for each experiment were exposed 2 to 4 mo prior to its start; suspended at depths of 0.5 to $2.0 \mathrm{~m}$ above the bottom from the Marine Sciences Institute pier in Noank. Connecticut, USA near the mouth of the Mystic River.

Panels were examined every 1 to $2 \mathrm{wk}$ to assess the development of the sessile community. When a species or an assemblage of functionally and taxonomically related species (e.g. barnacles, encrusting bryozoans) began to dominate the panels, all other visible species were removed. These manipulations produced complete dominance by each taxon chosen.

\section{SERIES 1}

\section{Methods}

Two experiments were begun in July 1986. An assemblage of 3 species of barnacles, Balanus crenatus

Table 1. The 3 series of experiments conducted in 1986 and 1987. Series 1 experiments examined oyster larval (L) settlement and post-settlement juvenile $(\mathrm{J})$ growth and survival. Series 2 experiments tested specific hypotheses. In Series 3 , several Series 1 experiments were modified and repeated

\begin{tabular}{|c|c|c|c|c|}
\hline \multirow[t]{2}{*}{ Experiments } & \multicolumn{2}{|c|}{ Life stage examined } & \multirow[t]{2}{*}{ Design } & \multirow{2}{*}{$\begin{array}{c}\text { Possible } \\
\text { unmeasured } \\
\text { tank effect }\end{array}$} \\
\hline & Field & $\mathrm{Lab}$ & & \\
\hline \multicolumn{5}{|l|}{ Series 1} \\
\hline 1. Balanus spp. & $\mathrm{L}_{\imath} \mathrm{J}$ & L, J & Treatments isolated by tank & Yes \\
\hline 2. Ciona intestinalis & L, J & L, J & Treatments isolated by tank & Yes \\
\hline 3. Encrusting bryozoans & J & L, J & Replicate tanks with all treatments & No \\
\hline 4. Encrusting ascidians & $\mathrm{J}$ & $L, J$ & Replicate tanks with all treatments & No \\
\hline 5. Bugula turrita & $\mathrm{J}$ & $\mathrm{L}, \mathrm{J}$ & Replicate tanks with all treatments & No \\
\hline \multicolumn{5}{|l|}{ Series 2} \\
\hline 1 Turf & & $\mathrm{L}$ & Single tank & No \\
\hline $\begin{array}{l}\text { 2. Ciona intestinalis and } \\
\text { Styela clava predation }\end{array}$ & & $\mathrm{L}$ & Each species in $1 \tan k$ & No \\
\hline \multicolumn{5}{|l|}{ Series 3} \\
\hline $\begin{array}{l}\text { 1. Balanus spp. - } \\
\text { living and dead }\end{array}$ & & $\mathrm{L}$ & Treatments random in 1 tank & No \\
\hline 2. Botryllus schlosseri & & $\mathrm{L}$ & Replicate tanks with all treatments & No \\
\hline 3. Botrylloides sp. & & $\mathrm{L}$ & Replicate tanks with all treatments & No \\
\hline
\end{tabular}


(Bruguiere), B. improvisus (Darwin), and B. amphitrite (Darwin) was used in one experiment and the solitary ascidian Ciona intestinalis (L.) was used in the other. Another 3 experiments were begun in September 1986. Encrusting bryozoans, principally Schizoporella errata (Waters) or Cryptosula pallasiana (Moll), were used in the first experiment, 2 species of encrusting ascidians, Botryllus schlosseri (Pallas) or the recently introduced Botrylloides sp., were used in the second, and the erect bryozoan Bugula turrita (Desor) was used in the third.

In all 5 experiments, 3 density treatments were established: control (0\% cover), low density ( 30 to $50 \%$ cover), and high density (50 to $90 \%$ cover). All control panels were created by removal of all organisms. In the barnacle and Ciona experiments, the low and high density treatments were created by removing haphazardly excess individuals from panels to yield $50 \%$ and $90 \%$ cover, respectively. The ascidian, bryozoan, and Bugula experiments were begun before complete cover developed on all panels and panels were assigned to low and high density treatments based on their cover.

Ten panels of each treatment were exposed to competent oyster larvae in the laboratory to examine the effects of the test species on oyster settlement. After settlement data were collected ( $2 \mathrm{~d}$ ), oyster growth and survivorship were followed on all treatments by returning 5 replicates to the field site and holding the remaining 5 in the laboratory in continuously flowing seawater. The only source of food in the laboratory was that available in the incoming seawater.

Five additional replicates of each treatment of the barnacle and Ciona experiments were placed for $1 \mathrm{mo}$ in the Poquonnock estuary (a site near the Marine Sciences Institute known for good oyster recruitment) to measure natural oyster recruitment over weekly intervals. Apparent anoxic conditions at this site during the first week of exposure resulted in severe mortality of organisms on many of the treatment panels, particularly of Ciona. Some panels were replaced after the first sampling period, but a sufficient number of Ciona panels was not available. These panels were replaced by ones dominated by another solitary ascidian, Molgula manhattensis (DeKay). In the analysis the 2 species were treated as equal.

Settlement. The design of the settlement experiments balanced 3 concerns. Experiments needed to be conducted in a sufficiently large volume of water in order to allow normal larval behavior. Treatments could not affect each other (e.g. predation of larvae by a test species reducing the number of larvae available that could settle on control panels in the same tank). Finally, suitable replication (sensu Hurlbert 1984) was necessary

A sufficient water volume was maintained in all settlement experiments by exposing groups of panels in shallow $50 \mathrm{l}(50 \times 50 \times 20 \mathrm{~cm})$ sea-tables. In the barnacle and Ciona experiments, each treatment was assigned to a separate sea-table, thus preventing interactions between treatments. However, replication was suitable only if no differences, other than those caused by the treatments, were assumed to exist between sea-tables. A control panel was placed in each sea-table to compare differences between the tanks, and possible interactions between treatments were examined in an additional sea-table which contained 2 panels from each treatment in the 2 experiments. Results from the latter experiment indicated that treatment effects were quite local and the presence of different treatments in the same tank had little, if any, effect on the oyster settlement.

In the bryozoan, ascidian, and Bugula experiments, 5 control, low, and high density panels were both chosen and placed randomly in each of 2 separate sea-tables. This new design allowed us to analyze for tank effects in each of these experiments and unambiguously to use panels as replicates.

A constant number of oyster larvae were added to each sea-table within each group of experiments. In the barnacle and Ciona experiments, ca 30000 larvae were placed in each sea-table, resulting in 3000 larvae available for each panel. In the remaining 3 experiments, 15000 larvae were used per tank or ca 1000 larvae available for each panel. Panels were exposed to larvae for about $16 \mathrm{~h}$, after which time the majority of larvae had attached to the panels or to the walls of the sea-table. All panels were then moved to another seatable which had no larvae. Oysters attached to panel surfaces and to test species were counted and the panels were returned either to laboratory sea-tables or the field site. Because a very small number of oysters had attached to the high and low density Ciona panels, these panels were re-exposed to oyster larvae for another $16 \mathrm{~h}$ in order to increase oyster densities for subsequent survivorship analyses.

Post-settlement growth and mortality. After ca 1 mo, oyster survivorship and growth were measured on all field and laboratory substrates. It was assumed that oysters were the same size at settlement and growth was measured as the maximum diameter of each individual. On each panel the first 10 oysters which could be accurately sized were measured using a dissecting microscope with an ocular micrometer.

Assumptions and analysis. The total number of oysters attaching to each panel was assumed to measure the overall effect of a particular patch of habitat on settlement, regardless of microhabitat differences within that patch. No distinction was made between oysters attached to a test species or to open panel surface. Each panel was assumed to be a replicate 
substrate. In the barnacle and Ciona settlement experiments it was assumed that there was no tank effect other than that caused by the treatment. In all other settlement experiments tank effects were eliminated or measured. We assumed, based on the similarity in settlement onto isolated and grouped barnacle and Ciona panels (except the low density Ciona panels, Table 2), that substrates in the same tank had no measurable effect on other panels.

In all experiments, data were analyzed using analysis of variance (ANOVA). Tank effects could not be tested in the Ciona and barnacle experiments and a 1 way ANOVA was used. A block design (treatment $x$ tank) was used in the remaining experiments.

Analysis of total oyster settlement did not account for any variability within a patch of habitat in the settlement of oyster larvae. One measurable parameter that varied between patches was the amount of space occupied by each test species. In a second analysis we tested the hypothesis that each species affected settlement onto its own surface but not onto neighboring open panel surfaces. Because the relative availability of test species and open surfaces differed between treatments, we analyzed for differences between these surfaces using density of settling oysters rather than absolute number. If the resident species affected settlement only onto their own surfaces, then the density of oysters on panel surfaces would be the same between treatments, but this density would differ from that found on the species. However, if the residents also influenced settlement onto the adjacent panel surfaces, differences between treatments in settlement densities on these surfaces would exist.

In the barnacle and Ciona experiments we did not measure the space occupied by the test species and assumed 0,50 , and $90 \%$ cover in the 3 treatments. In addition, we estimated the area of a barnacle available for colonization as the lateral surface of a truncated cone. Based on the dimensions of the species, we assumed that barnacles increase the available surface area by a factor of 3 . Because only 1 oyster was found to settle on Ciona, data for this ascidian were not corrected.

In all other experiments we made estimates of the percent cover by the test species on each panel. Oyster settlement densities were calculated using these estimates. No corrections were made for area added in the third dimension by other species. Encrusting ascidians and bryozoans are fairly flat; however, Bugula was estimated as canopy, so that space occupied by this species may be overestimated.

Oyster survivorship was followed on laboratory and field panels. In all experiments, a 2-way ANOVA was used to estimate the effects of the 3 density treatments and 2 sites (field and laboratory). In the barnacle and
Ciona experiments, data were collected $39 \mathrm{~d}$ after oyster settlement and in the remaining 3 experiments data were collected after $30 \mathrm{~d}$.

Growth data were collected at the same time as the survivorship data. Because several oysters were measured on each replicate panel, panels were treated as a third variable in the ANOVA model with oysters nested by panels within sites.

\section{Results}

Total settlement

Differences in the mean number of oysters settling on each type of panel were highly significant in all Series 1 experiments (Table 2, Fig. 1). Except for the Ciona experiment in which the controls were significantly higher than the other 2 treatments, mean number of

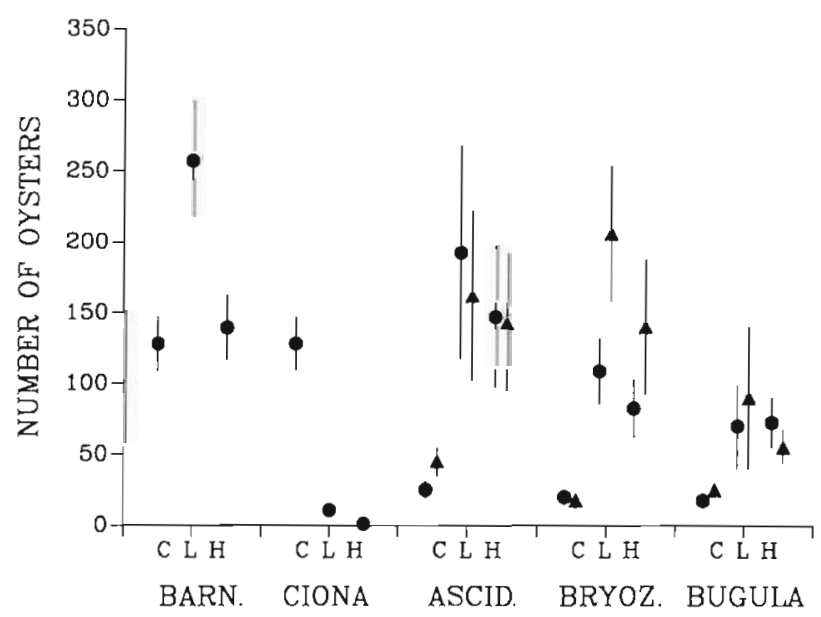

Fig. 1. Crassostrea virginica. Comparison of total settlement (mean $\pm 1 \mathrm{SE}$ ) in the 5 Series 1 oyster settlement experiments. Within each experiment the 3 density treatments were: $C$,

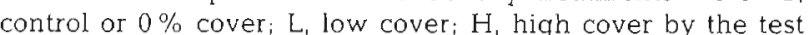
species. Circles and triangles are for different treatment tanks (ascidian, bryozoan, or Bugula experiments)

oysters settling was lowest on control panels and highest on low density treatments. In all experiments, differences in settlement between control and low density treatments were significant. High density treatments, with intermediate settlement, were also intermediate in their relationship to the extremes and significantly different from controls in the ascidian and bryozoan experiments. Finally, a significant difference between panels in different sea-tables was found in the bryozoan experiment but not in the ascidian or Bugula experiments. 


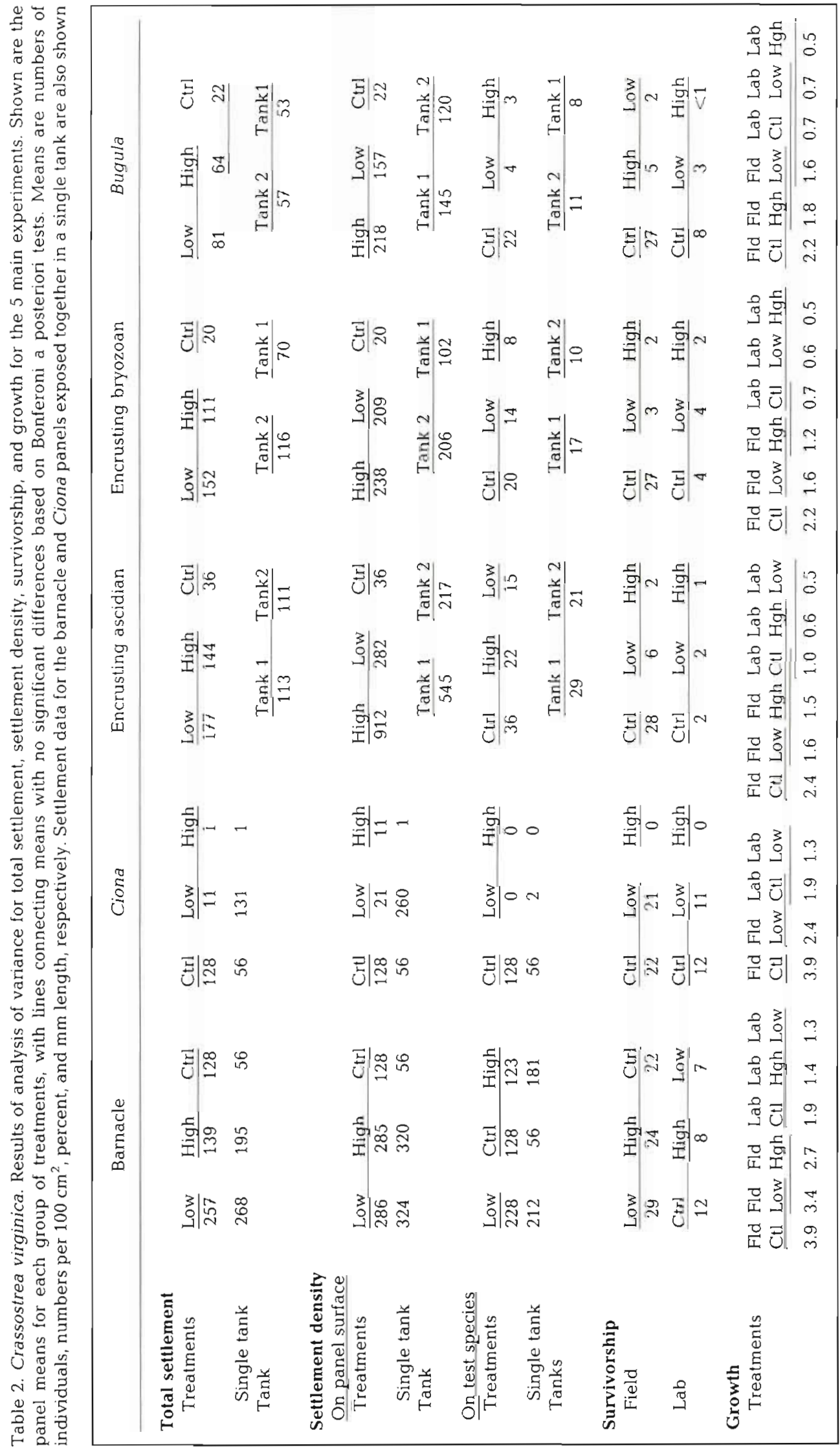




\section{Settlement densities}

Patterns of oyster settlement density were very similar among the Series 1 experiments (Table 2, Fig. 2). In all except the Ciona experiment, oysters settled in higher densities on open surfaces of panels with test species, than control panels (but not significant for barnacles). In
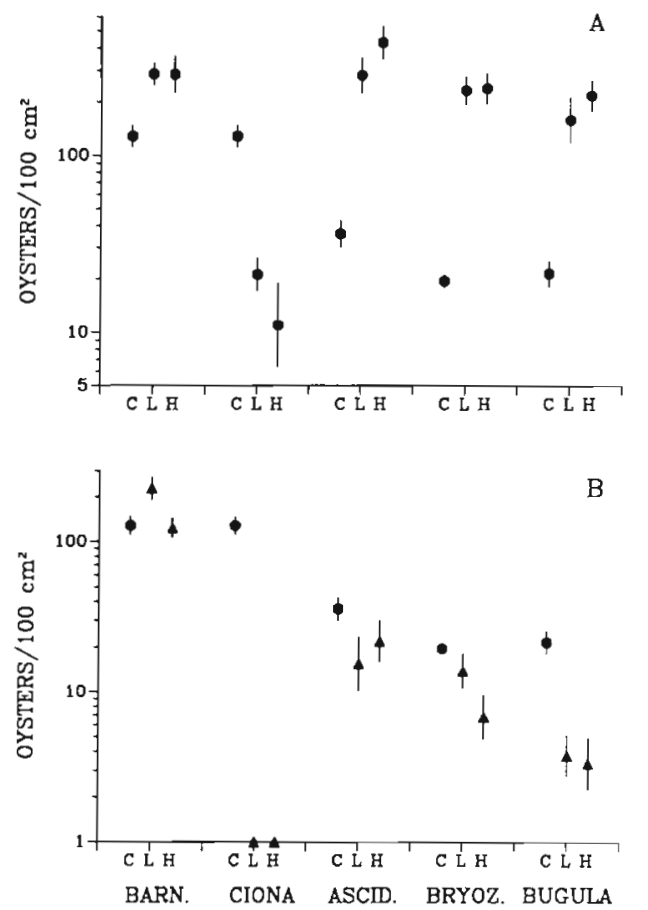

Fig. 2. Crassostrea virginica. Comparison of oyster settlement density (mean $\pm 1 \mathrm{SE}$ ) in the 5 Series 1 oyster experiments. (A) Panel surface. (B) Surface of the test species (4); panel surface (•). X-axis legend as in Fig. 1

contrast, settlement densities were significantly less on surfaces of test species than on the adjacent panel surface (except for barnacles), and with 2 exceptions (bryozoans and colonial ascidians) these densities were also significantly less than on control panels. There were no significant tank effects on settlement density on panel surfaces. However, small significant differences were found between tanks in the densities of oysters on encrusting ascidians and bryozoans.

\section{Field recruitment}

Oysters recruited onto experimental panels in the Poquonnock River during only one of the sampling periods. As in the laboratory experiments, there were significant differences in total recruitment among treatments (Table 3). Oyster recruitment was significantly greater on control panels than on both the low and high
Table 3. Crassostrea virginica. Analysis of variance of field recruitment of oysters onto panels of 5 different treatments, and a posteriori comparisons of treatment means. Treatments connected by lines are not significantly different $(p>0.05)$

\begin{tabular}{lrrrrr|}
\hline Source & Df & SS & MS & $F$ & $p$ \\
\hline Treatment & 4 & 348.70 & 87.17 & 3.21 & 0.0302 \\
Error & 24 & 651.51 & 27.15 & & \\
Total & 28 & 1000.21 & & & \\
Duncan grouping & Mean & & Treatment & \\
\hline & & 8.875 & & Control \\
& & 4.000 & $50 \%$ Barnacle \\
& & 1.800 & $50 \%$ Ascidian \\
& & 0.500 & $90 \%$ Ascidian \\
& & 0.167 & $90 \%$ Barnacle \\
\hline
\end{tabular}

density solitary ascidian panels and the high density barnacle panels. No significant difference was found between the control and the low density barnacle treatment.

\section{Survivorship}

For survivorship analyses, no distinction was made between individuals on the panel surface and those on the test species. Except in the barnacle experiment, there was only incidental survivorship of individuals on test species. It was impossible to determine whether this was a consequence of the initially low numbers on test species or an actual effect of the species.

In all but the barnacle experiment there were significant differences in survivorship among field treatments (Table 2). In all experiments, mean survivorship on field control panels was between 20 and $30 \%$. This was reduced to between 1 and $8 \%$ in the presence of encrusting bryozoans, encrusting ascidians, and Bugula. Differences were also observed in the Ciona experiment, but this probably was more a consequence of the lack of settlement on the high density treatments rather than mortality differences.

In all experiments, survivorship on panels in the field was usually at least twice that observed on panels held in the laboratory (Fig. 3). Survivorship was much higher on the field control panels than in most other treatments (including laboratory control panels). Although the patterns among laboratory treatments were generally the same as those for field panels, differences were seldom significant (Table 2).

In addition to the quantitative data:

(1) In all experiments, treatments, and sites we found fully articulated shells of dead individuals on the panels.

(2) Dead individuals were of all sizes, including individuals no larger than those newly settled and others 

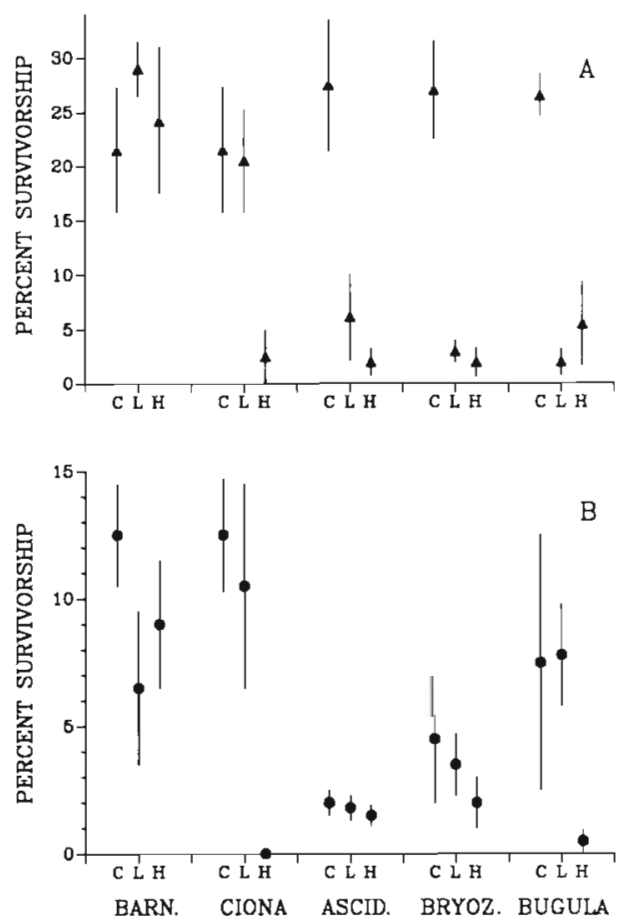

Fig. 3. Crassostrea virginica. Comparison of oyster survivorship (mean $\pm 1 \mathrm{SE}$ ) after ca 1 mo in the 5 Series 1 experiments. (A) Means for panels at the field site. (B) Means for panels kept in the laboratory. $\mathrm{X}$-axis legend as in Fig. 1

that were as large as the largest living individuals observed.

(3) At least 8 individuals were found whose death apparently resulted from overgrowth by encrusting bryozoans, including 5 by Schizoporella, 2 by Cryptosula, and 1 by Membranipora sp. These individuals could only be seen through the semi-transparent growing edge of the colony and do not reflect the total number overgrown. The largest individual was $1.5 \mathrm{~mm}$ in size.

(4) On one panel a Botrylloides colony regressed, exposing the panel surface it had overgrown. In the exposed area 69 dead oysters were observed. Also exposed, near what would have been the edge of the colony when it was at its maximum size, were 2 living oysters, each $3 \mathrm{~mm}$ in diameter. These larger individuals were apparently able to survive a short period of overgrowth.

\section{Growth}

Both treatment and site had significant effects on oyster growth in all Series 1 experiments. In the barnacle, Ciona, and encrusting bryozoan experiments, there were significant differences among panels within treatment and site (Table 2). As with survivorship, mean oyster growth on all treatments in the field was more than twice the growth on the same treatments in the laboratory (Fig. 4). Also, in all but the Bugula experiment, oyster growth on field control panels was significantly higher than that observed on the high abundance treatments. The sizes of oysters on low abundance treatments were intermediate but significantly
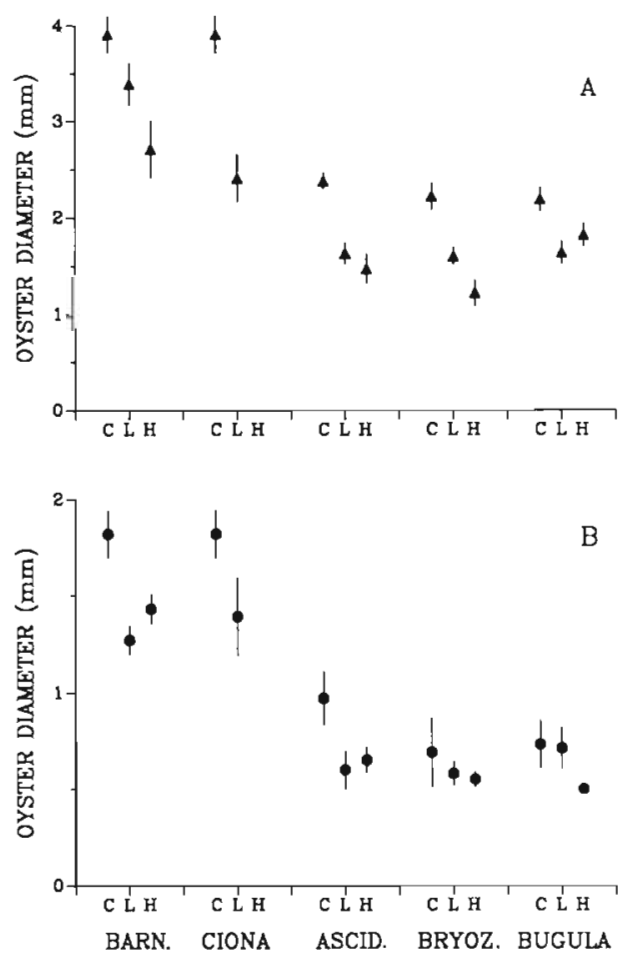

Fig. 4. Crassostrea virginica. Comparison of oyster growth (mean $\pm 1 \mathrm{SE}$ ) in (A) field and (B) laboratory during the first month after settlement. $X$-axis legend as in Fig. 1

different from the control panels in only the Ciona and encrusting bryozoan experiments. With the very low growth rates in the laboratory, no significant differences were found among treatments in any of the experiments. However, in all experiments mean growth was higher on control panels than on the treatments with test species.

\section{SERIES 2}

\section{Methods}

Two laboratory experiments were conducted to test new hypotheses that resulted from analyses of Series 1 experiments. The first experiment examined whether the removal of a 'turf' of encrusting protozoans, diatoms, sediment, and small individuals of a variety of invertebrate species on the panel surface affected oyster settlement. This 'turf' was most efficiently removed 
in the control treatments and to a lesser degree in the low density treatments. The effect of this removal was examined by comparing settlement of oysters onto panels completely scraped (as in the normal control treatments) and panels on which all large invertebrates were removed but the 'turf' was allowed to remain. Five panels of each treatment were exposed together in a single sea-table. Procedures were similar to other settlement experiments.

During the settlement experiments, Ciona was observed to ingest large numbers of oyster larvae and the feeding experiments were conducted to determine whether larval predation could contribute to the strong negative effect of Ciona on oyster settlement. In the second experiment larvae were placed in tanks with actively feeding Ciona or the recently introduced solitary ascidian Styela clava (Herdman). For each species, 6 panels containing 30 individuals were placed in separate aerated seawater tables. To each table 105000 oyster larvae were added and after $22 \mathrm{~h}$ a $15 \mathrm{ml}$ water sample and ascidian fecal material were collected to determine the number of larvae removed and whether any survived ingestion. First, 5 individual pellets were removed from the bottom of each tank with a pipette and preserved in separate vials. The remainder of the pellets were then collected in a similar manner and preserved in one bulk sample. Bulk collections of pellets were again made $5 \mathrm{~d}$ later. The numbers of oyster larvae in individual fecal pellets were counted and bulk samples were used to estimate the total number of larvae ingested by the 2 species.

\section{Results}

\section{Effect of turf}

The presence of turf had a highly significant effect on oyster settlement (Table 4). In the presence of turf, total settlement was more the 5 times greater than when turf was removed by scraping the panel. This difference is similar to that seen between oyster densities on control and treatment panels.

\section{Predation by solitary ascidians}

We found that over a $22 \mathrm{~h}$ period, predation by Ciona could account for the loss of $29 \%$ of the larvae added (Table 5). Predation by Styela clava accounted for a loss of $96 \%$ of all larvae to which it was exposed. In neither experiment were oyster larvae found in water samples taken at the end of $22 \mathrm{~h}$, indicating that all of the larvae had either been ingested by each species and/or settled. Fecal pellets of Ciona contained fewer oyster
Table 4. Crassostrea virginica. Analysis of variance of oyster settlement on control panels with turf and without turf (completely scraped)

\begin{tabular}{|c|c|c|c|c|c|}
\hline Source & Df & SS & MS & F & $p$ \\
\hline Treatment & 1 & 255154.050 & 255154.050 & 36.374 & $<0.0001$ \\
\hline \multirow[t]{4}{*}{ Error } & 18 & 126265.700 & 7014.761 & & \\
\hline & & \multicolumn{2}{|c|}{ Mean number of oysters } & & \\
\hline & & Turf & No turf & & \\
\hline & & 262 & 35 & & \\
\hline
\end{tabular}

Täble 5. Crassostrea virginica. Results of Ciona intestinalis and Styela clava feeding experiments. To determine the total number of oyster larvae in the bulk fecal pellet collections after $22 \mathrm{~h}$, a $0.01 \mathrm{ml}$ suspension of the collected fecal pellets was removed and all the larvae were counted under a dissecting microscope. Total numbers were then estimated based on the total volume of fecal pellets

\begin{tabular}{|lcc|} 
& \multicolumn{2}{c|}{ Test species } \\
& Ciona & Styela \\
\hline No. larvae added & 105000 & 105000 \\
Total volume of fecal pellets & $1.80 \mathrm{ml}$ & $1.25 \mathrm{ml}$ \\
No. larvae / 0.01 ml & 168 & 816 \\
Total no. larvae in bulk sample & 30240 & 102000 \\
$\%$ of larvae added present in & $29 \%$ & $96 \%$ \\
fecal pellets & & \\
Mean \# $( \pm 1$ SD) of larvae & $47.4 \pm 87.35$ & $94.4 \pm 51.31$ \\
per pellet $(n=5)$ & $1-203$ & $40-175$ \\
Range & & \\
\hline
\end{tabular}

larvae than those of Styela, but subsequent collections indicated that Ciona continued to produce fecal pellets containing larvae, while the number of larvae in Styela pellets had diminished. This suggests that Ciona had a longer gut retention time than Styela and ingested more larvae than indicated by the $22 \mathrm{~h}$ fecal pellet collections.

\section{SERIES 3}

\section{Methods}

Two sets of experiments were conducted as part of Series 3. First, an experiment was conducted to examine in more detail the effects of barnacles on oyster settlement and to eliminate differences among experimental tanks that may have influenced the results of the Series 1 barnacle experiment. This experiment was also designed to compare the effects on oyster settlement of living barnacles and empty barnacle tests. Second, 2 experiments were conducted to determine the individual effects of the 2 colonial asci- 
dians, Botryllus and Botrylloides, on oyster settlement. The design was the same as that used in the Series 1 ascidian experiment except that each species was examined separately. Thus these experiments examined the repeatability of the experimental results of Series 1 and isolated the effects of the 2 species on oyster settlement and recruitment.

Barnacle experiment. In February 1987, clean panels were exposed at the Mystic River field site. By May these panels were covered by barnacles and 50 panels were collected and manipulated to produce 10 control, 20 low, and 20 high density treatments, at 0,40 to 60 , and 90 to $100 \%$ cover, respectively. Ten panels of each of treatment were returned to racks at the field site and the remaining 10 panels of the low and high density treatments were dried on the dock for $2 \mathrm{wk}$ and then returned to the water with 10 new control panels (immersion controls). This resulted in 10 panels of each of 6 treatments: regular and immersion controls and high and low densities of living and dead barnacles.

The experiment was initiated in June 1987, in a large $(100 \times 217 \times 16 \mathrm{~cm})$, aerated tank of filtered (5 to $10 \mu \mathrm{m}$ ) seawater. All 60 panels were randomly placed in $6 \times 10$ rectangular array in the center of the tank. Approximately 740000 oyster larvae were added to the tank for a $12 \mathrm{~h}$ period. Panels were then removed to other tanks with flowing seawater and the number of attached oysters counted. Counts were made of oyster settling on panel surfaces, on barnacle tests, and inside dead barnacles.

Ascidian experiments. Panels at the field site were manipulated to obtain high and low coverage of the Botryllus and Botrylloides. In July 1987 these were collected in addition to control panels and placed in laboratory sea-tables. Three sea-tables were used for each species with each tank containing 5 replicate panels of each of the 3 density treatments with low and high density panels having 40 to $50 \%$ and 80 to $90 \%$ cover, respectively. Both the assignment of panels to tanks and the position of the panels inside the tanks were random. After $24 \mathrm{~h}$, ca 30000 oyster larvae were added to each tank. After $10 \mathrm{~h}$, the number of oysters attached to the panels and to the ascidians was counted.

\section{Results}

\section{Barnacle experiment}

Oyster settling patterns in this experiment were very similar to those observed in the 1986 Series 1 experiment. Living barnacles had a positive effect on the total number of oysters settling onto experimental panels (Fig. 5). However, unlike the 1986 experiment, settlement onto high and low density panels was equivalent. Settlement onto dead barnacle panels also exceeded levels on control panels, but this settlement was significantly less than observed on panels with living barnacles. A nested ANOVA indicated

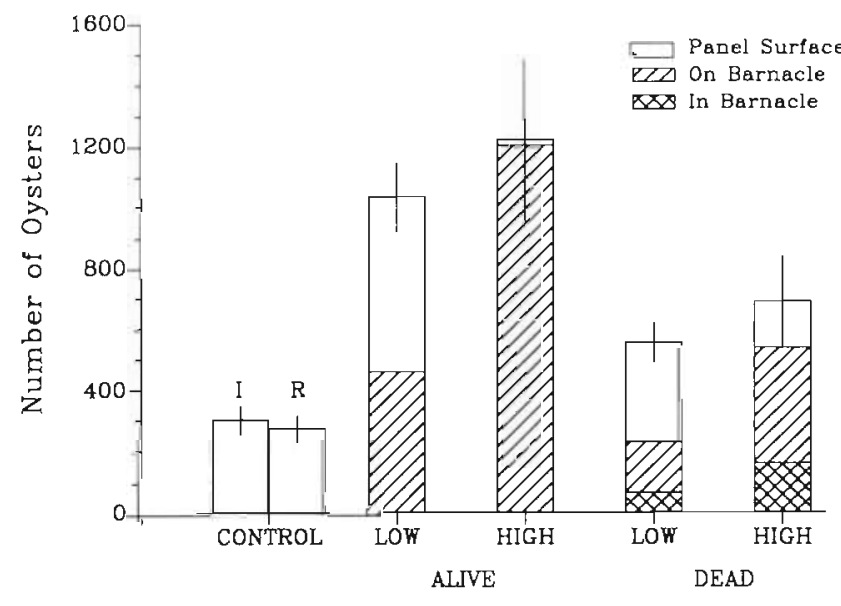

Fig. 5. Crassostrea virginica. Differences in total oyster settlement (mean $\pm 1 \mathrm{SD}$ ) among the 6 treatments in the 1987 Series 3 barnacle experiment. Two control treatments were used, one scraped and immersed for $2 \mathrm{wk}$ with the living barnacle treatments $(\mathrm{R}=$ regular control $)$ and one not immersed ( $=$ immersion control)

that both the main effect, barnacle density $\left(F_{2,57}=\right.$ $11.43, p<0.001$ ), and the nested variable, whether barnacles were alive or dead $\left(F_{3,57}=4.29, p<0.01\right)$ had significant effects on the total number of oysters settling. The results were the same when the analysis was repeated using only the number of oysters settling on open panel surfaces. Oysters settled in greater or equal numbers in open areas of low density barnacle panels relative to control panels even though there was only half the amount of free space. Settlement in the small amount of open space on high density panels was significantly lower than on control panels as would be expected.

\section{Second ascidian experiments}

For both Botryllus and Botrylloides, oyster settlement onto panels containing these species was greater at low cover or equivalent at high cover to that found on control panels (Fig. 6). As in the Series 1 experiment, most oysters attached to the panel surface, resulting in significantly higher densities than on ascidian colonies. Oyster densities on panel surfaces of high as well as low treatments were significantly greater than densities on controls. These patterns duplicate our previous results with encrusting ascidians, except that the density (but not total settlement) of oysters on high 

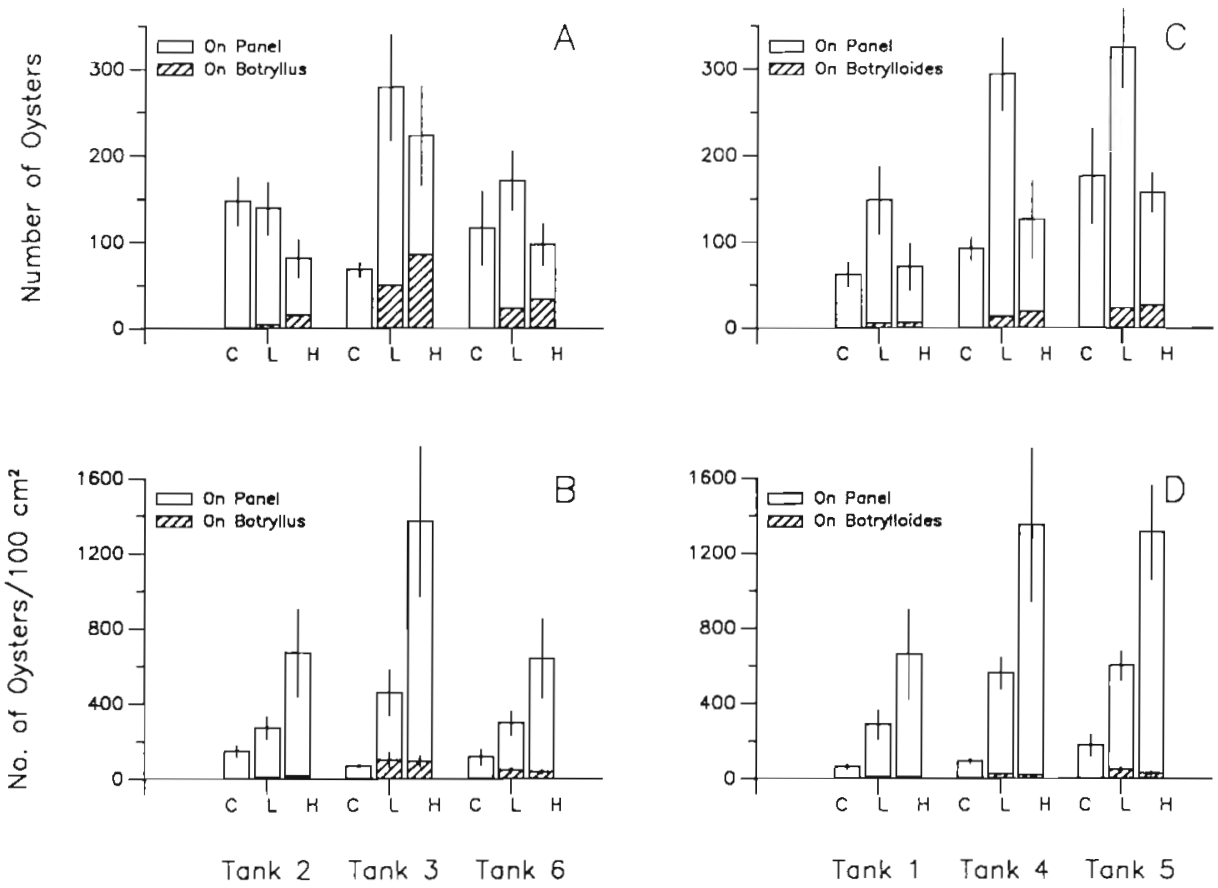

Fig.6. Crassostrea virginica. Differences in total oyster settlement and oyster density in the 1987 Series 3 Botryllus schlosseri and Botrylloides sp. experiments. (A) Number of oysters in Botryllus experiment. (B) Oyster density in Botryllus experiment. (C) Number of oysters in Botrylloides experiment. (D) Oyster density in Botrylloides experiment. Error bars represent standard deviation

density treatments was significantly greater than the density on the low treatments.

There were significant differences between experimental tanks in oyster settlement for both Botryllus and Botrylloides (Fig. 6). However, with the exception of the results for Botryllus in Tank 2, the relative effects of the treatments were the same in all tanks. Although the numbers of oysters settling differed between tanks within treatments, the treatment effects were significant for each species, both when the place of settlement was differentiated and for total settlement. The most likely cause of tank differences in these, as well as other experiments, was variability in the actual number of oyster larvae added to each tank.

\section{DISCUSSION}

Our results demonstrate that common sessile invertebrates can affect settlement and recruitment of at least one species, Crassostrea virginica. Resident species tested represent the phyletic, morphological, behavioral, and functional diversity found in most hard substrate communities, and include colonial and solitary, upright and encrusting, and calcareous and noncalcareous species. All are suspension feeders, but the bryozoans and the colonial ascidians are not capable of eating particles as large as oyster larvae. Upright species such as Bugula or barnacles do not overgrow young oysters, although barnacles can undercut them.
Even though resident species varied in their potential influence on oyster recruitment, several general conclusions can be drawn:

(1) Few oysters were able to settle onto and subsequently survive on surfaces of all resident species except barnacles. Bryozoans, colonial ascidians, and Ciona are able to keep most invertebrates from attaching to their external surfaces and as such these species represented 'poor' substrate for oysters. However, densities of oysters on adjacent panel surfaces were always high and usually higher than on control panels and this resulted in a positive affect of the residents on the total settlement of oysters. The cause of these increased densities is not clear. Increased contact of larvae with panel surfaces could result from feeding currents or a disruption of boundary layers as a consequence of the topographic relief added by residents. Larvae also could be attracted chemically to the test species.

In addition, the results of the turf experiment suggest that the removal of small invertebrates, detritus, and protozoans on control panels contributed to the lower settlement on these panels in many experiments. Cole \& Knight-Jones (1949), for example, found similar decreases in the settlement of Ostrea edulis on clean shell substrate when compared to shells with 1 to $4 \mathrm{wk}$ of fouling. Also, when all treatments from the Series 1 barnacle and Ciona experiments were placed in a single tank, controls had less than half the oysters than the isolated controls in the main experiments (Table 2). In contrast, of the other treatments only the low density 
Ciona panels were significantly different from identical treatments in the main experiments and control panels in the single tank experiment did not differ from control panels in the bryozoan, ascidian, or Bugula experiments which were in tanks together with the other treatments. This suggests that the high densities on controls in the first Series 1 experiments in part resulted from the absence of preferable substrate with turf.

The turf experiment can also explain results from the field recruitment experiments. Because recruitment data were collected after a week of exposure and control panels were not scraped after the weekly analyses, some turf would have been present on these panels prior to the observed recruitment. Thus, recruitment would be highest on controls because they had the greatest amount of available surface and this surface was of equal 'quality' as that found on the other treatments.

Both barnacle experiments clearly show that unlike other species, barnacles do not inhibit settlement on their shells. Although oyster settlement was high on and near both living barnacles and dead barnacle shells, the greatly increased settlement in the presence of living barnacles suggests that either the activities of these organisms or their exudates have a much stronger effect than shell chemistry or increased microtopography. The highest total settlement was on panels with high densities of living barnacles, and with little free space, most oyster larvae settled on barnacles. However, once larvae were close to barnacles, they appeared to select open space over barnacle shell. Higher settlement occurred on panel surfaces than on barnacle surfaces in low density treatments even though equal proportions of each existed (but 3 times more surface area for barnacle shells).

(2) The Ciona and Styela experiments demonstrate that sessile species can affect strongly local settlement by preying on larvae. Both species are capable of ingesting large numbers of oyster larvae and can reduce settlement on adjacent surfaces. This predation was local, apparently limited to the individual panels on which the species were present. The results of the experiment in which barnacle, Ciona, and control panels were all exposed to oyster larvae adjacent to one another in the same sea-table support this conclusion. Settlement on barnacle panels in this tank was no different than observed in the main experiment even though Ciona continued to prey on larvae.

(3) Both post-settlement survivorship and growth of oysters were strongly affected by the presence of most other sessile species. Survivorship decreased with an increase in the abundance of all species except barnacles. Oyster growth was reduced in the presence of all species tested.
The similarity in the patterns of oyster growth and survivorship among very different species suggesets that similar processes caused the patterns. Potential causes of increased mortality and reduced growth rate are predation, competition for space, competition for food, and differences in physical environment. Although each of these is important, competition for food may be the principal process producing the patterns.

First, both higher survivorship and growth in the field than in the laboratory most likely resulted from reduced food in the laboratory, if the volume of water flowing through the sea-tables did not have a sufficient supply of phytoplankton. Because the growth of other species was also reduced in the laboratory, higher rather than lower oyster survivorship should have occurred there if space competition were a principal cause of mortality. Predation could cause the lower growth and survivorship in the laboratory only if predators were more abundant there (or were forced by confinement to consume more oysters) and selectively preyed on larger individuals. We observed no predation on settled oysters.

Second, higher growth and survivorship on control than on treatment panels is also consistent with competition for food. Overgrowth could result in the reduction in survivorship on the treatment panels, but a reduction in growth would result only if larger individuals were preferentially overgrown. Likewise, if the presence of the test species resulted in higher numbers of predators then predation could have contributed to decreased survivorship. As with space competition, larger individuals would have to have been selectively ingested to produce the observed size decrease.

Third, observations of overgrowth on the bryozoan and ascidian panels did implicate space competition in these 2 experiments, but these species are also competitors for food.

Finally, the observation of many intact, dead oyster shells on the panels is generally inconsistent with space competition and predation by many species. We would expect most overgrown oysters to be completely covered and hidden and most predators would have damaged or removed the upper valve of the oyster.

Regardless of the cause it remains clear that adults of several sessile species can have profound effects on oyster recruitment, by affecting settlement and early mortality. The effects of the species are both general (e.g. the removal of available substrate) and specific (e.g. decreased survivorship resulting from overgrowth by encrusting bryozoans). The benthic assemblage inhabiting a local patch can affect critically recruitment making it more than a simple function of larval availability. Areas along a coast can differ in the number of 
recruits not only as a result of variations in the supply of larvae, but also from the disparate effects of resident adults on settlement and post-settlement mortality and growth.

Although daily settlement has been measured in the field (e.g. McDougall 1943, Connell 1961, Wethey 1984), recruitment is usually measured at time intervals of 1 to 6 wk (e.g. Osman 1977, Sutherland \& Karlson 1977, Sousa 1979). This difference between settlement and recruitment can be seen by comparing the number of oysters settling (Fig. 1) to the number surviving after $1 \mathrm{mo}$ (Fig. 7), i.e. recruitment. Barnacles, with no differences in oyster survivorship among treatments, show the same effect on the patterns of oyster settlement and recruitment. The lower oyster survivor-

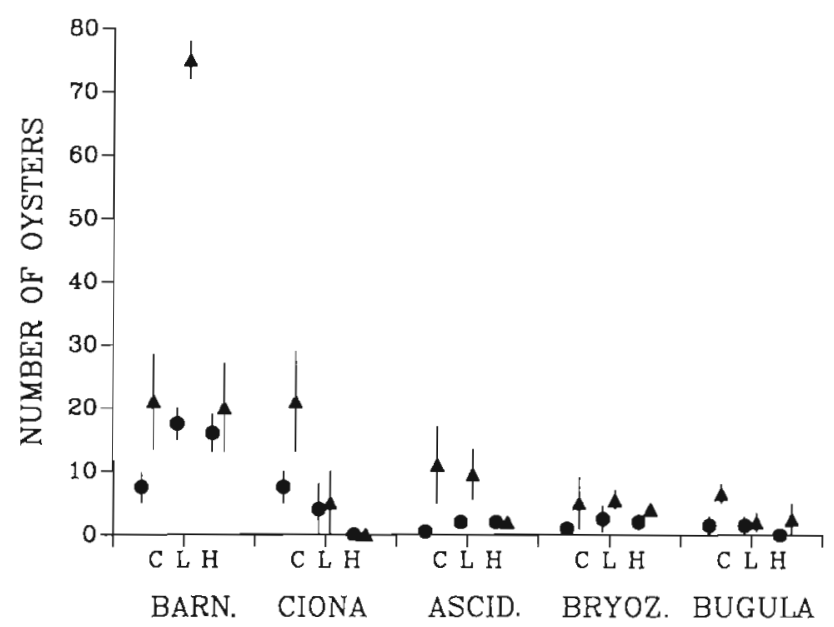

Fig.7. Crassostrea virginica. Comparison of the number of 1 mo old oysters that had recruited onto panels in the 5 Series 1 experiments (mean $\pm 1 \mathrm{SE}$ ). (ム) Panels at the field site panels kept in the laboratory

ship with increasing Ciona abundance intensified the latter's already strong effect on oyster settlement. However, in the encrusting bryozoan, encrusting ascidian, and Bugula experiments low settlement on the species coupled with the opposing effects of increased settlement on adjacent substrate and decreased survivorship in the presence of these same species resulted in no net effect of these species on oyster recruitment.

By measuring only net recruitment we severely underestimate the actual settlement occurring, the post-settlement mortality, and the potential for resident species to affect this process, particularly if the species have opposite effects on settlement and mortality. Also, the effects of residents on growth rates, quite possibly resulting from competition for food, would be completely missed. Differences in growth rate among individuals in the same cohort could not be distinguished from those resulting from differences in age or time of settlement. Recent studies, both empirical and theoretical (see references cited in 'Introduction'), have stressed the importance of recruitment processes within a diversity of communities. Processes affecting actual settlement and mortality in the post-settlement and juvenile lifestages can have a disproportionate affect on eventual adult population densities. Whether or not the resident community has a strong influence on recruitment (as in the oyster) will determine if the community is ultimately a product of settlement and post-settlement interactions or adult-adult interactions.

Acknowledgements. Without the excellent assistance of Edwin Rhodes (National Marine Fisheries Service Laboratory Milford, CT, USA) in supplying oyster larvae, this project would not have been possible. We also thank J. Griffith L. Gypson and B. Lussier for technical assistance and D. Breitburg and J. Sanders for reviewing the manuscript. This research was supported by grants from the Jessie B. Cox Charitable Trust and Sea Grant funds (NOAA Grant NA85AA-D-SG101), and is Contribution No. 210 of the University of Connecticut, Marine Sciences Institute.

\section{LITERATURE CITED}

Baggerman, B. (1953). Spatfall and transport of Cardium edule L. Archs néerl. Zool. 10: 315-342

Barnett, B. E., Crisp. D. J. (1979). Laboratory studies of gregarious settlement in Balanus balanoides and Elminius modestus in relation to competition between these species. J. mar. biol. Ass. U. K. 59: 581-590

Butman, C. A. (1987). Larval settlement of soft-sediment invertebrates: the spatial scales of pattern explained by active habitat selection and the emerging role of hydrodynamical processes. Oceanogr. mar. Biol. A. Rev. 25: 113-165

Caffey, H. M. (1985). Spatial and temporal variation in settlement and recruitment of intertidal barnacles. Ecol Monogr. 55: 313-332

Chia, F. S., Rice, M. E. (ed.) (1978). Settlement and metamorphosis of marine invertebrate larvae. Elsevier, New York

Cole, H. A., Knight-Jones, E. W. (1949). The setting behaviour of the European flat oyster Ostrea edulis L., and its influence on methods of cultivation and spat collection. Fish. Invest., Ser. 2, 17: 1-39

Connell, J. C. (1961). Effects of competition, predation by Thais lapillus, and other factors on natural populations of the barnacle Balanus balanoides. Ecol. Monogr. 31: $61-104$

Crisp, D. J. (1974). Factors influencing the settlement of marine invertebrate larvae. In: Grant, P. T., Mackie, A. M. (ed.) Chemoreception in marine organisms. Academic Press, New York, p. 177-265

Crisp, D. J., Knight-Jones, E. W. (1953). The mechanism of aggregation in barnacle populations. J. Anim. Ecol. 22: 360-362

Day, R., McEdward, L. (1984). Aspects of the physiology and ecology of pelagic larvae of marine benthic invertebrates. In: Steidinger, K. A., Walker, L. M. (ed.) Marine plankton life cycle strategies. CRS Press, Boca Raton, Florida, p. 93-120

Dixon, J. (1981). Evidence of gregarious settlement in the 
larvae of the marine snail Collisella strigatella (Carpenter) Veliger 24: 181-184

Eckman, J. E (1983). Hydrodynamic processes affecting benthic recruitment. Limnol. Oceanogr 28: 241-257

Gallagher, E. D., Jumars, P. A., Trueblood, D. D. (1983) Facilitation of soft-bottom benthic succession of tube builders. Ecology 64: 1200-1216

Gotelli, N. J. (1987). Spatial and temporal patterns of reproduction, larval settlement, and recruitment of the compound ascidian Aplidium stellatum. Mar. Biol. 94: 45-51

Gray, J. S. (1974). Animal sediment relationships. Oceanogr. mar Biol. A. Rev. 12: 223-261

Grosberg, R. K. (1982). Intertidal zonation of barnacles: the influence of planktonic zonation of larvae on vertical distribution of adults. Ecology 63: 894-899

Hannan, C. A. (1984). Planktonic larvae may act like passive particles in turbulent near-bottom flow. Limnol. Oceanogr. 29: $1108-1116$

Hurlbert, S. H. (1984). Pseudoreplication and the design of ecological field experiments. Ecol. Monogr. 54: 187-211

Jensen, R. A., Morse, D. E. (1984). Intraspecific facilitation of larval recruitment: gregarious settlement of the polychaete Phragmatopoma california (Fewkes). J. exp. mar Biol. Ecol. 83: $107-126$

McDougall, K. D. (1943). Sessile marine invertebrates of Beaufort, North Carolina. Ecol. Monogr. 13: 321-374

Meadows, P. S., Campbell, J. I. (1972). Habitat selection by aquatic invertebrates. Adv. mar. Biol. 10: 271-382

Mileikovsky, S. A. (1969). About the relation between the breeding and the spawning of marine invertebrates with pelagic development and their interspecial interrelationships as adults in bottom communities and as larvae in the plankton. Limnologica 7: 181-183

Osman, R. W. (1977). The establishment and development of a marine epifaunal community. Ecol. Monogr. 47: 37-63

Pratt, D. M. (1953). Abundance and growth of Venus mercenaria and Callocardia morrhuana in relation to the character of bottom sediments. J. mar. Res. 12: 60-74

Roughgarden, J., Iwasa, Y., Baxter, C. (1985). Demography theory for an open marine population with space-lmited recruitment. Ecology 66: 54-67

Sale, P. F. (1977). Maintenance of high diversity in coral reef fish communities. Am. Nat. 111: 337-359

Sale, P. F. (1978). Chance patterns of demographic change in population of territorial fish in coral rubble patches at Heron Island. J. exp. mar Biol. Ecol. 34: 233-243

Sale, P. F. (1979). Recruitment, loss and coexistence in a guild of territorial reef fishes. Oecologia (Berl.) 42: 159-177

Sale, P. F. (1982). Stock-recruit relationships and regional coexistence in a lottery competitive system: a simulation study. Am. Nat. 120: 139-159

This article was submitted to the editor
Scheltema, R. S. (1974). Biological interactions determining larval settlement of marine invertebrates. Thalassia jugosl. 10: $263-296$

Scheltema, R. S., Williams, I. P., Shaw, M. A., Loudon, C. (1981). Gregarious settlement by the larvae of Hydroides dianthus (Polychaeta: Serpulidae). Mar Ecol. Prog. Ser. 5: $69-74$

Schmidt, G. H. (1982). Random and aggregate settlement in some sessile marine invertebrates. Mar Ecol. Prog. Ser 9: $97-100$

Sousa, W. P. (1979). Experimental investigations of disturbance and ecological succession in a rocky intertidal algal community. Ecol. Monogr. 49: 227-254

Sutherland, J. P., Karlson, R. H. (1977). Development and stability of the fouling community at Beaufort, North Carolina. Ecol. Monogr. 47: 425-446

Thorson, G. (1966). Some factors influencing the recruitment and establishment of marine benthic communities. Neth. J. Sea Res. 3: 267-293

Todd, C. D., Doyle, R. W. (1981). Reproductive strategies of marine benthic invertebrates: a settlement-timing hypothesis. Mar. Ecol. Prog. Ser. 4: 75-83

Underwood, A. J., Denley, E. J., (1984). Paradigms, explanations and generalizations in models for the structure of intertidal communities on rocky shores. In: Strong, D. R. Jr., Simberloff, D., Abele, L. G., Thistle, A. B. (ed.) Ecological communities: conceptual issues and the evidence. Princeton Univ. Press. Princeton, New Jersey, p. 191-180

Wethey, D. S. (1984). Spatial pattern in barnacle settlement day to day changes during the settlement season. J. mar. biol. Ass. U. K. 64: 687-698

Wethey, D. S. (1985). Catastrophe, extinction, and species diversity: a rocky intertidal example. Ecology 66: 445-456

Whitlatch, R. B., Zajac, R. N. (1985). Biotic interactions among estuarine infaunal opportunistic species. Mar. Ecol. Prog. Ser 21: 299-311

Woodin, S. A. (1976). Adult-larval interactions in dense infaunal assemblages: patterns of abundance. J. mar. Res. 34: $25-41$

Woodin, S. A. (1978). Settlement phenomena: the significance of functional groups. In: Stancyk, S. (ed.) Reproductive ecology of marine invertebrates. Univ. South Carolina Press, Columbia, South Carolina, p. 99-106

Woodin, S. A. (1983). Biotic interactions in recent marine sedimentary environments. In: Tevesz, M. J. S., McCall, P. L. (ed.) Biotic interactions in recent and fossil benthic communities. Plenum, New York, p. 3-83

Young, C. M., Chia, F. S. (1984). Microhabitat-associated variability in survival and growth of subtidal solitary ascidians during the first 21 days after settlement. Mar. Biol. 81: $61-68$

Manuscript first received: February 29, 1988

Revised version accepted: March 23, 1989 